\title{
Interatividade e produção discursiva no rádio e na televisão: a participação da audiência e a conformação da mensagem informativa
}

\author{
Interactivity and discursive production on radio and television: audience \\ participation and conformation of the informational message
}

\author{
Suely Maciel $^{1}$ \\ (suelymaciel@faac.unesp.br) \\ Valquíria Aparecida Passos Kneipp ${ }^{2}$ \\ (valquiriakneipp@yahoo.com.br) \\ http://dx.doi.org/10.5216/cei.v15i1.22506
}

\begin{abstract}
Resumo
O estudo investiga a constituição da mensagem informativa nos processos de produção interativa nas mídias sonora e televisiva, a partir de situações em que conteúdos realizados pela audiência são veiculados. $\mathrm{O}$ trabalho mostra que as estratégias enunciativas empregadas pelos ouvintes e telespectadores efetivam-se sob uma série de controles e coerções discursivas decorrentes da própria dinâmica de produção nos meios e da relação que se estabelece entre emissora/programa e seu público. Além disso, percebe-se que, apesar das tentativas de produzir um efeito de independência do telespectador e do ouvinte em relação a sua participação e opinião, ocorre um direcionamento e um cerceamento relativo das possibilidades de expressão que, mais que técnico-operacionais, são de ordem discursiva.
\end{abstract}

Palavras-chave: Interatividade. Comunicação discursiva. Jornalismo. Rádio. Televisão.

\begin{abstract}
The study investigates the constitution of the informational message in production processes in interactive media and television, from situations in which contents are conveyed performed by the audience. The work shows that the declared strategies employed by listeners and viewers actualize itself in a series of controls and discursive constraints resulting from the dynamics in the means of production and the relationship established between broadcaster/program and its audience. Moreover, it is clear that, despite attempts to produce an effect independent of viewer and listener regarding your participation and opinion, there is a direction and a restriction on the possibilities of expression rather than technical, operational, are of discursive order.
\end{abstract}

Keywords: Interactivity. Discursive Communication. Journalism. Radio. Television.

\section{Introdução}

A possibilidade de interatividade, ou seja, de alternâncias dinâmicas de papéis, simultâneas

\footnotetext{
1 Doutor em ciências da comunicação pela Universidade São Paulo (USP), docente da Universidade Estadual Paulista (UNESP). Brasil, São Paulo.

2 Doutoranda em ciências da comunicação pela Universidade São Paulo (USP). Brasil, São Paulo.
} 
ou não, entre os sujeitos participantes do ato comunicativo, tem sido sobremaneira ampliada e diversificada na contemporaneidade, em virtude dos novos aparatos técnicos e da crescente demanda por participação. Isso coloca novos desafios para a comunicação nas mídias, exigindo dos veículos uma postura diferenciada na interlocução com seus públicos e na abertura de espaços para a atuação destes.

No caso da produção da mensagem informativa, no entanto, pode-se dizer que a participação da audiência ainda se encontra envolvida num debate cheio de melindres, pois, afinal, ela configura a possibilidade de ocupação, por parte de ouvintes e telespectadores, de um lugar simbólico até então prerrogativa de profissionais do jornalismo. A despeito disso e ainda que seja bastante tímida a participação da audiência de 'corpo/voz' no vídeo ou no rádio, tem sido cada vez mais comum a veiculação de produções do público, normalmente mediadas pelas equipes responsáveis pelos programas (leitura de tweets, cobertura de assuntos a partir de sugestões de pauta dos ouvintes/telespectadores etc.). Tal abertura, ainda que com restrições, é um processo irreversível, pois a interatividade, conforme Duguet (apud GOSCIOLA, 2003, 87-88) "promove no espectador uma mobilização, um desejo de interferir, de se relacionar com a obra e com seus personagens". E esse incremento da participação é um estímulo a pesquisas que busquem compreender as alternativas de interatividade em voga, bem como a conformação dos enunciados resultantes do processo interativo e sua repercussão no universo da produção jornalística nas mídias eletrônicas.

Em vista disso, a presente discussão toma como objeto a interatividade em duas produções distintas, no rádio e na televisão. No caso do primeiro, o estudo recai sobre diálogos entre apresentador e ouvinte em um quadro, dentro de um radiojornal, cujo foco é a informação sobre trânsito, passada justamente pelo público. Já na televisão, faz-se uma breve leitura de reportagens, realizadas pelo telespectador e veiculadas em um telejornal.

\section{Interatividade e produção de sentidos na comunicação}

Os parâmetros teóricos que balizam a discussão centram-se num entendimento diferenciado da interatividade e da relação entre os sujeitos da comunicação discursiva. No caso da comunicação midiática, a compreensão mais comum nos estudos do campo é a de que os processos interativos se efetivam entre dois polos, quais sejam, aquele que se responsabiliza pela produção e transmissão das mensagens e aquele que as recepciona, isto é, o destinatário/audiência/público. Eles são geralmente encarados como espaços em que se efetivam processos discursivos isolados, independentes e estanques, mesmo que se reconheça, numa maior ou menor medida, a sua 
complementaridade.

A ideia de interatividade que norteia a presente leitura, porém, é a de relação reciprocamente ativa entre os participantes da comunicação discursiva, em que não há divisão nem distanciamento entre 'polo emissor' e 'polo receptor'. Ao contrário, entende-se que a comunicação só se efetiva a partir de trocas enunciativas simultâneas e da mútua influência, ou seja, da permanente atitude responsiva ativa entre os sujeitos envolvidos no processo de interação discursiva, inerentemente dialógica (BAKTHIN, 2003). Isso abarca tanto falante e destinatário imediatos - ou seja, aqueles que, por exemplo, participam de uma conversação imediata, face a face, ou mediada por algum aparato, como o telefone - quanto os presumidos, isto é, o auditório mais amplo com o qual o enunciado dialoga. Não se trata, portanto, de interatividade entre indivíduos, mas de comunicação forjada discursivamente entre sujeitos. Tal noção é subsidiária do princípio do dialogismo, postulado por Mikhail Bakhtin ao longo de sua obra.

Segundo o teórico russo, os discursos, os sujeitos, a significação se definem em relação à interlocução imediata, mas também em relação aos dizeres passados e futuros, ainda que não concretamente materializados. O diálogo é condição de existência da linguagem e de todas as suas formas de realização. Estas formas se efetivam por meio de enunciados concretos, constituídos e em perene circulação nas diferentes esferas da comunicação humana (BAKHTIN, 2003), entre elas a midiática. Assim, a interatividade é inerente à dinâmica enunciativa e seu fundamento está na relação interpessoal e não apenas na relação homem-máquina ou homem-homem intermediada pela máquina, como o fenômeno da interatividade tem sido maciçamente enfocado na atualidade.

Pode-se afirmar, então, que a uma interatividade aparente, manifesta, subjaz uma outra, que está "sempre lá" e marca o caráter eminentemente interativo da comunicação discursiva dialógica. O fato de o 'outro' sempre se colocar em posição responsiva ativa em relação ao seu interlocutor, atuando na conformação do enunciado é uma mostra pontual dessa dinâmica. Em vista disso, limitar os processos interativos apenas às trocas imediatas entre falante e destinatário - em geral viabilizadas por algum aparato físico/tecnológico, como carta, telefone, e-mail, conversação face a face etc. - é estreitar sobremaneira a compreensão do fenômeno e de suas implicações.

A compreensão responsiva ativa, sempre 'lá', atua diretamente no desencadeamento do enunciado e seu sentido, mesmo que ela não se manifeste de forma aparente, como, por exemplo, num ato de fala ou num gesto consciente. Como, então, identificar essa relação em enunciados concretos, em especial produtos radiofônicos e televisivos de informação, em que a troca dinâmica entre enunciador (instância de 'produção') e destinatário (instância de 'recepção') se dá 
manifestamente, como quando ouvinte e telespectador produzem a mensagem transmitida? Uma possibilidade é justamente investigar as relações estabelecidas na interlocução imediata e na dimensão interativa ampliada, uma vez que, fora desse 'entorno' dialógico, não há atividade de linguagem possível.

Para tanto, no enfrentamento do enunciado e seu sentido deve-se em conta o horizonte espacial comum dos interlocutores, o conhecimento, a compreensão e a avaliação comum da situação, em suma, o aspecto intrinsecamente 'compartilhado' que se efetiva, no enunciado, entre duas instâncias de interlocução, bem como os aspectos históricos, sociais, culturais etc. que engendram a comunicação discursiva (BRAIT, 2004, 70). Por isso, tanto quanto se debruçar sobre as situações concretas, como a conversa entre apresentador de rádio/ouvinte e a presença do telespectador no vídeo como protagonista da produção, é importante identificar os fatores desencadeantes da interlocução e os parâmetros em que ela se dá, determinados pela linguagem do meio em que ela ocorre, a linha editorial, a temática e o formato do programa, os recursos técnicos viabilizadores da interlocução etc.

Nesse sentido, devem ser objeto de leitura na análise dos discursos radiofônico e televisivo todos os componentes da mensagem: a palavra e sua vocalização, as imagens, a sonoplastia (na forma de inserções musicais, efeitos sonoros e outros recursos), o cenário, a gestualidade dos falantes, os padrões gráficos etc., uma vez que a integração de códigos e gêneros é uma das características intrínsecas das mídias. Em vista disso, a constituição do enunciado se dá como numa espécie de 'mosaico', no qual todos os elementos (sonoros+musicais+verbais+gestuais...) perdem sua unidade isolada e passam a se articular simultaneamente.

\section{Interatividade e produção da mensagem na mídia radiofônica}

A leitura da interatividade na mídia radiofônica parte de duas situações exemplares retiradas do quadro "Ouvinte repórter Eldorado", segmento do radiojornal Jornal Eldorado, edição matinal, da rádio Eldorado AM, de São Paulo (SP), programa transmitido de segunda a sábado, das 5 h30 às 10h, para a região metropolitana de São Paulo.

O Jornal Eldorado é um programa jornalístico que se insere nos moldes tradicionais do formato, privilegiando as informações políticas, econômicas e locais. Sua estrutura encontra-se alicerçada no texto verbal, com uso moderado e pouco diversificado da sonoplastia, na forma de vinhetas, cortinas, BG etc. O quadro "Ouvinte repórter Eldorado" segue este padrão e tem como característica principal o foco na informação do trânsito na cidade, dada pelos ouvintes, 
durante um diálogo entre o apresentador-âncora e o público, que entra em contato com a emissora, via telefone. A ligação é colocada no ar, sem qualquer triagem prévia ou orientação sobre como o ouvinte deve se comportar. A conversa entre este o apresentador-âncora se dá numa intervenção direta e imediata, de viva-voz, e vai ao ar no momento em que ocorre diretamente no fluxo de mensagens do programa. Os diálogos duram, em média, um minuto, com alternância constante do turno de vozes entre os interlocutores (apresentador e ouvinte).

No quadro, ocorre um misto de participação tematizada e de prestação de serviços (McLEISH, 2001, p. 14). O ouvinte apresenta dados sobre as vias que formam seu trajeto, informando sobre situações de lentidão, congestionamento ou tráfego livre em ruas, avenidas e estradas. Às informações passadas pela audiência somam-se outras do mesmo tipo, transmitidas por um repórter especializado no assunto, ao longo de todo o radiojornal. Tem-se, portanto, duas origens de dados sobre o trânsito dentro do programa: uma ligada à equipe de jornalismo (repórter) e outra, independente e exterior a esta e à estrutura da rádio (ouvinte).

$\mathrm{Na}$ análise dos diálogos dentro do "Ouvinte repórter Eldorado", identifica-se uma regularidade nos procedimentos enunciativos do falante - no caso, o apresentador do programa - e do(s) destinatário(s) imediato(s), o(s) ouvinte(s) que liga (m) para participar do quadro. Além de atuarem diretamente na conformação do enunciado e seu sentido, tais estratégias revelam um conhecimento e uma compreensão partilhados sobre a situação, os quais têm como lastro os princípios editoriais da emissora, bem como a proposta e a estruturação do programa, conformados discursivamente. Tal conformação acaba determinando a estrutura do diálogo e da mensagem dele resultante, ao estabelecer contornos e limitações composicionais e temáticas para ambos.

No caso dos procedimentos enunciativos empregadas pelo apresentador durante o programa, particularmente quanto aos elementos paralinguísticos do enunciado verbal (variações de ritmo, entonação, ênfase e intensidade da voz)3, destaca-se um tom médio, grave e constante, configurando uma apresentação sóbria, elegante e reservada, mesmo nos momentos em que ocorre uma conversação mais próxima e amigável com os ouvintes. Isso contribui para imprimir nos enunciados um caráter de autoridade profissional, credibilidade e verossimilhança (BALSEBRE, 2005, p. 332).

Quando ocorre a interlocução de viva-voz, o ouvinte mantém o mesmo tom e faz a

\footnotetext{
3 De acordo com Armand Balsebre, as variações paralinguísticas, ou seja, alternâncias do som da vocalização, contribuem para o estabelecimento de contornos espaciais e multiperspectivistas para as 'imagens sonoras'. No caso de vozes dos locutores, as mais graves dão sensação de presença e proximidade. As mais agudas, de distância, inteligibilidade e claridade. (cf. BALSEBRE, A. A linguagem radiofônica. In: MEDITSCH, E. (Org.). Teorias do rádio: textos e contextos. Florianópolis: Insular. p.327-36).
} 
adequação de sua fala aos parâmetros que conformam o estilo jornalístico. As escolhas na composição do enunciado revelam discernimento sobre o tipo de construção que se convoca nesta situação específica (informações ligeiras sobre a dinâmica do tráfego na cidade, dadas sempre com o emprego de determinadas expressões) e a proposta por trás da interlocução. Para mostrar essas características e como a interatividade se efetiva, o presente texto discute dois momentos de interlocução entre apresentador-âncora e ouvinte. Antes, porém, tomam-se como ponto de partida exemplos de entradas do repórter especializado em trânsito, transcritas a seguir ${ }^{4}$ :

a) Repórter

$\mathrm{R}$ - Trânsito lento na Avenida Brás Leme para quem deixa a região de Santana em direção à Marginal Tietê Ponte da Casa Verde. A avenida Olavo Fontoura tem trânsito bom. Na praça Campo de Bagatele, o motorista reduz a velocidade em direção ao vale do Anhangabaú. A Avenida Cruzeiro do Sul ainda é (agudo) o melhor caminho.

$\mathrm{R}$ - (tudo acelerado) $\mathrm{O}$ trânsito está difícil para o motorista na zona sul da cidade : por causa de um acidente : antes na Ponte do Morumbi para quem vem de Santo Amaro em direção à Rodovia Castelo Branco. Homens da polícia militar já no atendimento, o motorista se possível deve evitar, quem tiver na região ali no Centro Empresarial pode utilizar a Giovani Gronchi, evitando esse congestionamento antes da ponte do Morumbi no sentido Butantã (mais alto) Castelo Branco.

Os dois textos do repórter apresentam características que se reiteram: dados sobre a situação do trânsito em pontos específicos da cidade, nomes de logradouros, descrição sobre estado do fluxo de veículos e suas causas, apresentação de rotas alternativas e localização espacial. Parte-se de um tópico, como a situação em uma localidade específica, e a ele vão-se adicionando pormenores e desdobramentos, numa progressão típica da estrutura de pirâmide invertida (ordem decrescente de importância na apresentação dos dados). Mantém-se o mesmo tom de voz em praticamente toda a participação, com poucas variações de altura e ritmo (similar às nuances da apresentação), o que contribui para a clareza e progressão da mensagem.

A participação do ouvinte, ainda que com os mesmos objetivos, efetiva-se numa estrutura diferente. Afinal, ela se dá por meio de um diálogo com o apresentador, enquanto as informações do repórter surgem na forma de um texto corrido, sem interposição de outras vozes. Observam-se,

\footnotetext{
4

As marcações em todos os textos radiofônicos transcritos dizem respeito às nuances da vocalização e são relativas basicamente à intensidade (ênfase leve, marcada com sublinhado/ênfase forte, em MAIÚSCULAS), ao volume (alto/médio/baixo), ao ritmo ou duração (acelerado/pausado/normal), ao intervalo (curto, médio, longo, assinalados com a marcação ::) e ao tom ou altura (grave-descendente/agudoascendente).
} 
então, dois exemplos de diálogo no quadro "Ouvinte repórter Eldorado"

b) Ouvinte (s)

$\mathrm{O} 1$

Apresentador-âncora - São seis e cinquenta e quatro minutos, agora é a vez do Lourenço. Bom dia, Lourenço!

O - Bom dia, Caio Camargo:: Ééé : eu queria complementar a informação do (mais baixo) Jair Rafael ${ }^{5}$...

A - Pois não.

$\mathrm{O}$ - ... eu cheguei agora na Ponte do Piqueri e a marginal já sentido :

Dutra, né, já está parada tanto na expressa quanto na : na pista marginal. Eu tô fazendo um caminho alternativo que é pela rua da Balsa, passando por trás da Editora Abril, pretendo sair atrás do prédio do Estadão de forma a pegar : o sentido da da zona norte. : Tá tudo livre por aqui.

A - Muito obrigado, Lourenço!Um bom dia!

$\mathrm{O}$ - Bom dia, um abraço.

A - Um abraço a você.

$\mathrm{O} 2-$

Apresentador-âncora - Eduardo, oi ::: Eduardo, bom dia!

$\mathrm{O}$ - Bom dia.

A -Sua informação...

$\mathrm{O}$-ééeh :: eu : eu saí da granja, né, no quilômetro 21 e tem um aciden...e tô indo para capital, tem um acidente no sentido interior no quilômetro 20 um pouquinho antes do Rodoanel e tá um trânsito ooo : tá bem ::

(levemente mais agudo até o final) nossa pra você ter uma idéia, eu tô no quilômetro 14 ou 15 aqui e o trânsito tá até aqui,entendeu?

A - Perfeito.

$\mathrm{O}-(\mathrm{e}$ e ...)

A - Raposo Tavares com muitos problemas nesta manhã também de quartafeira, é isso?

$\mathrm{O}-E$, além do normal, né, sentido capital, a gente que tem todos os dias. Agora também quem tá indo em sentido interior tem aí a alternativa talvez. aí para quem ainda não pegou a Raposo : talvez seria pegar a Castelo e sair no Rodoanel, ou quem conhecer a a a região aqui, sair por dentro de Osasco e tentar, tentar aí alguma algumas vias aí por dentro de Osasco pra tentar sair no Rodoanel e sair na Raposo de novo já já depois ...

A - Perfeito.

$\mathrm{O}-$ (do acidente).

A -Porque a Castelo também há dificuldades viu? do quilômetro 18 ao 13

há também problemas, viu?

$\mathrm{O}$-Então hoje éh éh paciência (rindo) então, né?

A - Exatamente, Eduardo. Muito obrigado 
$\mathrm{O}-$ (imagina)

A - por sua informação!

$\mathrm{O}-$ (bom dia a todos)

A - ... Um bom dia!

$\mathrm{O}$ - (bem baixo) Um bom dia a todos. Té logo.

Comparando-se a informação do trânsito apresentada pelo repórter e aquela do público, identificam-se características que permitem entrever o 'saber' que este demonstra sobre o tipo de construção que se espera de sua participação de viva-voz. As pistas para identificar este domínio da situação e do formato a ser produzido, como se podem ver principalmente nos trechos em itálico, são a fala curta e limitada às informações do trânsito, a seleção vocabular (expressões simples, diretas e precisas, na medida do possível) e também a organização, a fluidez e a progressão do texto, pois, ainda que haja mais pausas e retificações se comparadas ao enunciado do repórter, isso é compreensível, tendo em vista que o texto do ouvinte surge numa situação de diálogo e de emprego informal da modalidade falada da linguagem verbal. Mesmo o uso de expressões típicas desta informalidade falada ("aí", "né” etc.) não chega a comprometer o enquadramento da mensagem sob os objetivos de uma típica nota informativa (FERRARETO, 2000). Além disso, os ouvintes relatam a situação do tráfego e, na sequência, informam sobre rotas alternativas, numa postura condizente com os propósitos do quadro, de prestação de serviços. Destaque-se ainda que não surgem no diálogo outras informações ou observações que não estejam relacionadas com o tema trânsito, nem se transgride o estilo 'correto' e polido característico de todo o programa.

O ouvinte em geral procede dessa forma no trato da informação não porque é um jornalista e profissional de rádio, mas porque apreende esse estilo que cerca o formato a partir do próprio contato que tem com ele, nas audições do radiojornal. Ou seja, o ouvinte passa a dominar o código e respeita a padronização tradicionalmente posta para a informação jornalística quanto à temática, à forma composicional e à escolha dos recursos lexicais, ainda que imprima uma ou outra marca de seu estilo próprio (na forma de variações vocabulares, entonação e ritmo), mas que não destoam do estilo do programa e da emissora.

Esse domínio não surge de imediato, como que por mágica, no momento em que se dá a interlocução com o apresentador-âncora, mas vai sendo construído paulatinamente a partir do contato que o ouvinte, via audição, tem com a programação da emissora, o programa específico em que o quadro se insere, as inúmeras interlocuções semelhantes à dele etc. Afinal de contas, antes de ser um 'falante' nas situações interativas de viva-voz, o ouvinte que participa do quadro faz parte do público do programa, ou seja, do destinatário presumido, de contornos imprecisos e ampliados, com 
o qual dialogam todas as interlocuções e mensagens efetivadas ao longo da programação. Isso reforça a noção de que o diálogo sempre se efetiva, ainda que os interlocutores não se encontrem em situações específicas de trocas enunciativas imediatas, face a face ou não.

É graças a este 'diálogo ampliado e ininterrupto' que o conhecimento e o domínio das estratégias discursivas específicas de cada situação tomam forma e os procedimentos enunciativos conformam-se aos objetivos da comunicação neste caso, que é a informação jornalística de prestação de serviços. A construção da mensagem no diálogo de viva-voz, portanto, sofre diversas coerções de ordem discursiva que acabam por circunscrever e limitar as possibilidades de expressão, apesar de, na aparência, a interlocução estar livre de qualquer amarra. Tais coerções decorrem também do fato de o emprego dos gêneros ser marcado pela esfera de comunicação concreta em que eles se realizam.

Os gêneros discursivos regulam, organizam, orientam e significam todo ato de linguagem e interação humana. Para o falante, eles constituem parâmetros sociais para a construção dos enunciados (quem sou eu que falo, quem é meu interlocutor, qual o propósito da minha fala etc.), enquanto para o destinatário funcionam como um certo horizonte de significação, pois dão "pistas" de como se processará a interação (NASCIMENTO; BARROS, 2007)

\footnotetext{
Conhecer determinado gênero significa, pois, ser capaz de prever certas 'coerções' que o condicionam, como, por exemplo, sua estrutura de composição ou suas regras de conduta, ou seja, o que é ou não adequado àquela determinada prática de linguagem. Assim, quanto mais competente (no sentido de dominar um gênero) for o indivíduo, mais proficiente ele será nos seus atos de linguagem e nas suas práticas sociais.
}

No "Ouvinte repórter Eldorado", o público destinatário presumido, colocado na posição também de falante quando do diálogo de viva-voz, realiza os propósitos definidos pela situação, ao dominar e empregar o código convocado por ela. Dessa forma, a provável credibilidade até então impressa sobre o formato e, por extensão, o trabalho jornalístico, encarnado pelo jornalista, passa a sê-lo também sobre o 'ouvinte' e sobre o enunciado que ele constrói nas situações interativas, ou seja, mensagem do público adquire o mesmo status daquela produzida pelo profissional. A interatividade, neste caso, promove o esmaecimento dos limites entre o lugar do sujeito que teria 'autoridade' sobre a informação (o jornalismo) e o lugar do sujeito que, em tese, deveria limitar-se a recebê-la (o público), sem que, no entanto, o propósito informativo da mensagem seja comprometido. 


\section{Interatividade e produção da mensagem na mídia televisiva}

A interatividade no telejornal trazida para a discussão assemelha-se à efetivada no rádio, pois também neste caso a audiência surge como produtora da mensagem, no caso, uma reportagem do "Parceiro do RJ", exibido dentro do telejornal diário local RJTV, transmitido pela Rede Globo de Televisão para o estado do Rio de Janeiro. O telejornal vai ao ar de segunda-feira a sábado, em duas edições, às $12 \mathrm{~h}$ e às 19 horas.

O quadro "Parceiro do RJ" foi implantado em janeiro de 2011 e é uma experiência nova dentro da Rede Globo, a principal emissora brasileira: mostrar a realidade de diferentes áreas da região metropolitana do Rio de Janeiro a partir dos próprios moradores, que se tornam responsáveis pela produção das matérias. As diretrizes do programa destacam, acerca do telespectador, que "é ele quem apresenta o lugar onde vive, com um olhar que só ele tem, produzindo conteúdo para o telejornal" (PARCEIRO DO RJ).

Diferentemente da experiência no rádio, em que não há cadastro ou avaliação prévios do ouvinte que entra no ar, os participantes da proposta da televisão fazem inscrição e passam por uma seleção (cujos critérios não foi possível apurar). $\mathrm{Na}$ atual temporada, os telespectadores selecionados entre os 2.200 inscritos fizeram prova de português, conhecimentos gerais, raciocínio lógico e redação, além de participarem de dinâmicas de grupo. No final do processo, ficaram 18 jovens de oito regiões metropolitanas fluminenses, mas atualmente apenas 16 participam. Eles estão organizados em duplas e receberam uma câmera para produzir as reportagens para o RJTV, após passarem por treinamento (PARCEIRO DO RJ).

Durante a elaboração das reportagens, os 'parceiros' são tutelados por profissionais da emissora, que acompanham todo o processo, supervisionando o material produzido; os profissionais também se encarregam da edição, mesmo com a supervisão do "parceiro". A produção da mensagem, portanto, é mais controlada nesta proposta de interatividade.

Numa aproximação ainda inicial sobre a iniciativa, toma-se como exemplo para a leitura uma reportagem de 2 minutos e 52 segundos exibida no dia 02 de março de 2011. Nela é possível identificar toda uma formatação padronizada do telejornalismo, com cabeça da matéria, off, sonora e passagem, como se pode ver abaixo, na transcrição do texto verbal e da estrutura que foi ao ar:

Cabeça:

Domingo agora, na praça do Ó, na Barra da Tijuca, tem a grande final do skate vertical, com transmissão ao vivo, dentro do Esporte Espetacular. Agora esse clima aí do mundial de skate levou os nossos parceiros do RJ em 
Nova Iguaçu, Mariana e Peter MC, a descobrir por lá a primeira pista de skate da América Latina. Dá uma olhada.

Abertura da repórter Mariana

É uma pequena prancha de madeira que faz a cabeça da galera aqui em Nova Iguaçu (sobe som ambiente) É a praça de skate e hoje vamos conhecer a sua pista histórica. Vamos dar um rolê?

Entra vinheta do programa, com música de fundo (funk), animação gráfica e texto vocalizado "parceiro do RJ no ar, rapá"

Sonora entrevistado 1, com inserção de imagens de arquivo:

A pista de skate começou na necessidade da gente de praticar o esporte na nossa idade não tinha muita alternativa para a nossa idade, e acabou a gente vendo em revistas tudo isso que foi feito aqui. $\mathrm{O}$ desenho foi meu, mas a ideia foi de uma geração.

Off da repórter:

E larga o skate dos seus 53 anos?

Sonora entrevistado 1:

não não não. É um estilo de vida

(sobe som)

sonora entrevistado 2

E inspirador, né, porque toda pessoa que é mais jovem ela que um dia chegar onde o mais velho chegou né, por exemplo, você tem aquela idade e continuar andando de skate assim com aquele ânimo é superlegal supermotivante

Sobe som

Sonora entrevistado 3

Para as gerações que cresceram vendo os antigos andar aqui, essa pista ela tem um valor histórico muito grande porque ela é a primeira da América Latina.

Off da repórter

Tô vendo que o senhor tá de calça jeans e camisa e mesmo assim dá pra andar de skate?

Sonora entrevistado 3

Dá. Não existe um estereótipo. O skate na verdade ele tá na alma né?

Sonora entrevistado 4 
Uma sensação como se estivesse pegando onda no concreto. Eu gosto muito da prática de surf e me apaixonei porque possibilita sentir a mesma emoção. Deslizá fazê as manobras, então eu não paro nunca.

Off da repórter

Agora as filhas acompanham o pai na pista. Como é isso?

Sonora entrevistado 4

E tá passando de geração em geração

off da repórter

tá no sangue?

Sonora entrevistado 4

tá no sangue tá no sangue

sonora entrevistado 5

é muito legal isso porque é um esporte que meu pai pratica desde que ele era mais novo

sonora entrevistado 6

eu acho bem divertido também andá de skate. Eu acho que é uma liberdade assim

Passagem da repórter

além de ser considerada a primeira pista de skate da América Latina, esta pista também já teve a visista de Bob Burnquist

Sonora entrevistado 7

meu primeiro contato como skate foi com 12 anos. Na época era um brinquedo ainda. Aqui foi que eu conhece as manobras e toda a cultura do skate.

Off da repórter

e vocês que frequentam a pista já há muito tempo, voces têm projeto para que ela se torne patrimônio histórico de Nova Iguaçu?

Sonora entrevistado 7

exatamente. Na verdade, nós queremos é proteger o patrimonio, né? Viabilizar recursos para que ele esteja em constante manutenção e resgatar a história de Nova Iguaçu

Sobe som com trilha sonora

Na matéria, identifica-se a estrutura formal de um reportagem televisiva, com off, passagem e sonora, além do respeito às normas estilísticas, vocabulares e de linguagem para o 
formato. É possível verificar certa liberdade de produção no que diz respeito ao texto verbal, que, conforme o exemplo acima apresenta gírias ("faz a cabeça da galera de Nova Iguaçu"; "vamos da um rolé?") e um tom mais informal. Isso, porém, não é uma transgressão ao estilo do programa, nem foge ao padrão editorial da emissora. É visível também a presença de membros da comunidade na matéria, haja vista que ocorre a inserção de sete entrevistados, o que confirma, pelo menos neste exemplo, a proposta do "Parceiro RJ": escolher jovens de comunidades do Rio de Janeiro "para contar a realidade de onde moram". A realidade que surge na reportagem, porém, coloca-se sob um matiz: a valorização da comunidade e dos moradores e suas iniciativas. Não há abertura para a apresentação de aspectos negativos do cotidiano do lugar, o que também se verifica em outras reportagens do quadro.

Outro ponto a se destacar é que, mesmo mantendo o controle de todo o material produzido pelo "parceiro" (uma vez que a edição fica a cargo da equipe do RJTV), o programa está abrindo um espaço novo para a interatividade, ao colocar o telespectador como produtor da mensagem. Em uma emissora como a Rede Globo, que viveu e conviveu historicamente com a ditadura militar brasileira e teve passagens polêmicas na trajetória de seus telejornais (como foi a campanha pelas diretas em 1989), não deixa de chamar a atenção a iniciativa de abrir o espaço editorial para a participação de jovens das comunidades periféricas. A presença do telespectador no vídeo, também comandando formatos tradicionalmente realizados por profissionais do jornalismo, parece uma tentativa de criar uma imagem mais alinhada com a crescente demanda por abertura e aproximação entre as instâncias emissora e receptora. Ressalte-se, porém, que também nesta iniciativa os controles discursivos se verificam, como adequação ao tipo de produção requerida (reportagem), o emprego de recursos de linguagem comuns às demais produções da atração, a observância da proposta temática do quadro e da linha editorial do programa e, por extensão, da emissora.

\section{Considerações Finais}

A leitura dos enunciados produzidos nas situações interativas no rádio e na televisão mostrou que os procedimentos enunciativos são determinados pelas próprias condições de produção da mensagem. Eles são também atravessados pelo projeto editorial dos programas e pelo universo de valores em que transita a proposta de programação e gestão das emissoras, identificados na escolha dos recursos de linguagem, no encadeamento e hierarquização das informações, na seleção temática etc. Todos esses fatores reunidos acabam por delimitar um lugar para a interlocução e para os sentidos que ela comunica. Os participantes das propostas interativas só podem dizer o que dizem por que os contornos do programa conformam seus enunciados: os procedimentos instauram 
a cumplicidade e a necessidade tácita de ratificar um determinado conjunto de ideias e atitudes, coerentes com os princípios norteadores dos projetos dos programas e das emissoras.

Disso decorre que as produções efetivadas sob a proposta de interatividade sofrem coerções tanto de ordem discursiva e ideológica quanto 'operacional', que são também da compleição que os veículos adquirem. A interatividade, assim, não surge como espaço totalmente aberto à afirmação de pontos de vista diferentes daqueles que norteiam a proposta das emissoras (maciçamente reforçados nos programas), mesmo que, em princípio, seja aberto o canal para que os pontos de vista 'de fora' se manifestem. Isso ocorre porque o destinatário já é conformado pelos procedimentos empregados na enunciação, ao mesmo tempo em que também atua sobre eles.

Em vista disso, fica claro que, por trás das tentativas de produzir um efeito de independência do ouvinte e do telespectador em relação à sua participação e opinião, ocorre um direcionamento e um cerceamento relativo das possibilidades de expressão e da manifestação de pontos de vista que não ratifiquem a orientação fixada tacitamente nas propostas interativas. Ressalte-se, contudo, que isso não decorre de 'intenções' isoladas de alguém e prescinde de controle pontual e específico; é, sim, um parâmetro fixado na própria dinâmica discursiva em que os enunciados tomam forma e são pronunciados.

Em vista disso, concretizar uma verdadeira e minimamente equilibrada participação da audiência pressupõe outra maneira de encarar as propostas interativas. O problema não é somente disponibilizar mecanismos para que o chamado público possa participar, mas, principalmente, compreender como a dinâmica discursiva se efetiva nos processos de comunicação nas mídias radiofônica e televisiva.

O paradigma corrente é o de que o aparato tecnológico favorece a aproximação interpessoal, ou a assunção de um lugar de produção, mais livre e em condições de igualdade entre os sujeitos participantes da comunicação. Na verdade, contudo, o controle permanece, pois ele é discursivo, não é mecânico. As coerções são inerentes ao processo discursivo, no movimento de interação entre o 'eu' e o 'outro'. Então, dar voz ao ouvinte e ao telespectador, permitir seu acesso aos programas, não é, nem de longe, garantia de mínimo equilíbrio nas relações, já que a igualdade entre elas é impossível, pois o discurso é o lugar do poder e do confronto de posições.

Se se quiser, portanto, construir realmente uma interatividade mais aberta e participativa em programas jornalísticos, como os trazidos no presente estudo, não basta disponibilizar o acesso aos aparatos ou abrir o canal para que o destinatário se revele e se manifeste. É preciso pensar desde a proposta editorial dos programas e as formas em que a interatividade de superfície realizar-se-á. 
Um último ponto a se destacar é que, nas situações trazidas para esta discussão, tanto ouvinte quanto telespectador, sob tutela ou não, aparecem desempenhando uma função normalmente considerada prerrogativa dos profissionais de jornalismo das emissoras. O público atua, nesse caso, como a origem de uma informação que se insere no mesmo nível daquelas produzidas e apresentadas por jornalistas. Isso, por si só, suscita uma discussão frutífera sobre informação, credibilidade e legitimidade e o lugar da informação jornalística num tempo em a demanda por propostas interativas e de abertura à participação do público nas produções midiáticas torna-se crescente e irreversível.

\section{Referências}

BAKHTIN, M. Estética da criação verbal. Trad. Paulo Bezerra. São Paulo: Martins Fontes, 2003. BALSEBRE, A. A linguagem radiofônica. In: MEDITSCH, E. (Org.). Teorias do rádio: textos e contextos. Florianópolis: Insular, 2003. p.327-36.

BRAIT, B. (Org.). Bakhtin, dialogismo e construção do sentido. Campinas/SP: Unicamp, 1997. FERRARETO, L. Rádio: o veículo, a história e a técnica. Porto Alegre: Sagra Luzzatto, 2000. GOSCIOLA, V. Roteiro para as novas mídias: do game à TV Interativa. São Paulo: SENAC, 2003.

McLEISH, R. Produção de rádio: um guia abrangente de produção radiofônica. São Paulo: Summus, 2001.

MESQUITA, J. L. Eldorado, a rádio cidadã. São Paulo: Terceiro Nome, 2008.

PARCEIRO DO RJ. Disponível em: <www.G1.globo.com/rio-de-janeiro/parceiro-rj>. Acesso em: 20 jan. 2012. 